\title{
Evaluation of the marginal accuracy of provisional restorations made of acrylic resins
}

Ísis Franco Pereira ${ }^{1}$, Emilena Maria Castor Xisto Lima,*

1 Graduate Student of Dentistry, Federal University of Bahia, Department of Clinical Dentistry, Salvador, Bahia, Brazil.

${ }^{1}$ Adjunct Professor of Bahiana School of Medicine and Public Health and Federal University of Bahia, Department of Clinical Dentistry, Salvador, Bahia, Brazil.

Corresponding author: Emilena Maria Castor Xisto Lima Rua Waldemar Falcão, n. 1906, Torre Paysage, apt. 1402 Horto Florestal

Salvador - Bahia CEP - 40295-010 Brazil

Tel: +55 (71) 99194-6656

E-mail: emilenalima@gmail.com

Received: September 09, 2018

Accepted: March 22, 2019

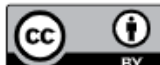

Aim: To evaluate the marginal accuracy of provisional crowns made of acrylics resins and to identify the surface(s) with the highest marginal discrepancy. Methods: A direct technique was used to fabricate 96 provisional restorations with 8 materials: Dencrilay, Dencôrlay, Dencôr, Vipicor, Duralay, Resinlay Speed, Refine Bright and Alike $(n=12)$. The provisional crowns were made on a prepared molar-shaped metal die with a vinyl polysiloxane impression as a matrix. Marginal discrepancy of provisional restorations was analyzed at buccal, lingual, mesial and distal surfaces of metal die finish line in a stereomicroscope lupe at 100X. The images obtained were transferred to the Corel Draw X7 program and the distances from the cervical margins of the specimen to the reference lines were measured vertically. Comparisons were made with 1-way analysis of variance and the Tukey test $(p<0.05)$. Results: The Alike resin exhibited the lowest marginal discrepancy $(0.018 \mathrm{~mm})$ and was significantly different from the Dencôrlay $(0.037 \mathrm{~mm})$, Refine Bright $(0.034 \mathrm{~mm})$, Duralay $(0.033 \mathrm{~mm})$ and Vipicor $(0.032)$ resins. The buccal surface showed the highest marginal discrepancy $(0.040 \mathrm{~mm})$ compared to those of other surfaces (distal $0.029 \mathrm{~mm}$, lingual $0.028 \mathrm{~mm}$ and mesial $0.024 \mathrm{~mm}$ ). Conclusion: The marginal adaptation of all materials and surfaces tested in this study were within a clinical acceptable limit. The Alike resin showed the best performance compared to Dencôrlay, Refine Bright, Duralay, and Vipicor resins. The buccal surface showed the highest marginal discrepancy than those of the other tested surfaces.

Keywords: Dental marginal adaptation. Dental restoration, temporary. Acrylic resins. 


\section{Introduction}

The availability of provisional restorations is a substantial advance for the field of prosthetic treatments. Provisional crowns are used as a diagnostic tool and can help maintain gingival health and protect the dental pulp and underlying preparation. Additionally, an optimum interim fixed restoration must satisfy interrelated biologic, mechanical, and aesthetic factors, including resistance to fracture, marginal fit, color stability, wear resistance, tissue compatibility, ease of manipulation, cost, prevent pillar teeth migration, and reestablish occlusal contact ${ }^{1}$.

One of the fundamental requirements for an adequate provisional restoration is acceptable marginal adaptation ${ }^{1-3}$. It is critical to obtain properly adapted margins to reduce the cement line width. Open marginal configurations encourage microleakage of bacteria and their by-products due to dissolution of the luting agentes ${ }^{3}$ and may predispose the tooth to caries or pulpitis ${ }^{4}$. In addition, poor marginal fit can cause mechanic irritation on surrounding tissues and increase the accumulation of biofilm, which causes subsequent periodontal problems including gingival inflammation, gingival bleeding and recession. These problems are more frequent in restorations with subgingival margins ${ }^{2,3}$.

The first provisional restorations were prefabricated in metal and plastic before the development of acrylic resins that could be directly manipulated. The bis-acrylic resins were developed later. The auto-polymerizing acrylic resins have similar colors as natural teeth, are easy to prepare and are low cost. These advantages have made the resins a popular material for provisional restorations ${ }^{5}$.

The most common materials used for the fabrication of the provisionals are polymethylmethacrylate (PMMA) resins and composite-based resins (CBR $)^{6,7}$. Since their introduction, PMMAs quickly became the most frequently used interim fixed prostheses material ${ }^{8}$. The characteristics of polymethyl methacrylate are acceptable color stability, relatively high shrinkage and may be polished, characterized, and repaired ${ }^{1,9}$.

The polymerization method, temperature, and environment where the resin is stored during and after the polymerization can interfere with the physical properties of acrylic resins (flexural strength, roughness, porosity, and dimensional stability) ${ }^{2,10}$ One of the inherent properties of polymer based interim materials is polymerization shrinkage, which causes dimensional changes that can adversely affect precise fit (marginal discrepancies and occlusal interferences) and lead to internal stresses within the restoration ${ }^{4}$. Moreover, provisional crowns made from different PMMA co-polymer materials show varying effects upon marginal adaptation ${ }^{11}$.

There are no restorative materials that meet all the ideal provisional restoration prerequisites ${ }^{5}$. The choice of provisional material used must be based on physical properties, manipulation method, durability, and cost. Therefore, dental professionals should choose materials based on the clinical needs of the patient 2,5 .

Thus, the aims of this study were to evaluate the marginal accuracy of provisional crowns made of acrylics resins and to identify the surface (s) with the highest marginal discrepancy. 


\section{MATERIAL AND METHODS}

A direct technique was used to fabricate 96 provisional restorations with 8 materials: Dencrilay, Dencôrlay, Dencôr, Vipicor, Duralay, Resinlay Speed, Refine Bright and Alike $(n=12)$. The provisional prosthetic materials used in this study are listed in table 1.

An in vitro method was used to simulate a direct clinical technique in which the provisional crown was made directly on the prepared tooth using vinyl polysiloxane impression as a matrix (Elite Double 16, Zhermack, BadiaPolesine - RO, Italy). A 37 macro model tooth was prepared for a complete metaloceramic crown with a 1-mm chamfer finish line and a taper of approximately 5 degrees. The prepared tooth was cast in a base metal alloy. A standard crown was fabricated for the prepared die to represent the form of the tooth prior to preparation. A matrix planned for provisional fabrication was used to copy the contours from the standard crown adapted to the metal die. A verticulator (Bio-art Equipamentos Odontológicos Ltda., São Carlos - SP, Brazil) was used to standardize the path of insertion and removal of the impression tray and the applied force.

After that, the metal die was lubricated (Vaseline, Quimidrol, Joinville, SC, Brazil) to prevent adhesion to the resin samples. The acrylic resins (table 1) were dispensed and mixed according to the manufacturer's instructions and placed into the matrix using a spatula (\#24). The resin-filled impression was adapted on the metal die with aid of the verticulator, which remained locked during polymerization. Before complete polymerization, excess of material was trimmed from the margins of the provisional restorations using a scalpel blade (15c). The provisional restorations were then allowed to polymerize completely in a water bath at ambiente temperature ${ }^{2,11,12}$. All procedures were performed by one operator calibrated.

Next, the provisional crowns were placed on the metal die and fixed with a " $\mathrm{C}$ " clamp (Metasul, Braço do Norte - SC, Brazil) during the analysis in a stereomicroscope lupe at 100X (Opton MDCE-5, USB 2.0, Hiperquímica, Santo André - SP, Brazil). Photos were taken of the buccal, lingual, mesial and distal surfaces and the images were transferred to the Corel Draw X7 program. The distances from the cervical margins of the specimen to the reference lines previously marked at the metal die (buccal, lingual, mesial and distal surfaces) were measured vertically. The measurements were made 3 times along the long axis of the die at each of the 4 reference points. All procedures were performed by one operator calibrated.

The amount of marginal discrepancy (mean of 12 measurements) was compared among the 8 provisional restoration materials with a 1- way analysis of variance (ANOVA) followed by the Tukey test for multiple comparisons $(p<0.05)$.

Table 1. Provisional prosthetic materials used in this study.

\begin{tabular}{lc}
\hline Acrylic resins & Manufacturer \\
\hline Dencrilay & Dencril (Dencril Produtos Odontológicos, Pirassununga - SP, Brazil) \\
\hline Dencôrlay & Clássico Artigos Odontológicos Clássico, São Paulo - SP, Brazil) \\
\hline Dencôr & Clássico Artigos Odontológicos Clássico, São Paulo - SP, Brazil) \\
\hline Vipicor & Vipi (Vipi Produtos Odontológicos, Pirassununga - SP, Brazil) \\
\hline Duralay & Reliance (Reliance Dental, Worth - IL, EUA) \\
\hline Resinlay Speed & TDV (TDV Dental Ltda., Pomerode - SC, Brazil) \\
\hline Refine Bright & Yamahachi/ Kota (Kota Imports, Cotia - SP, Brazil) \\
\hline Alike & GC (GC América, Alsip - IL, EUA) \\
\hline
\end{tabular}


The marginal discrepancy value of each surface was the arithmetic mean of these 3 measurements and the surfaces were compared with a 1- way analysis of variance (ANOVA) followed by the Tukey test $(p<0.05)$.

\section{RESULTS}

The means and standard deviations of the marginal discrepancy are represented in the table 2. The Alike resin exhibited the lowest marginal discrepancy mean $(0.018 \mathrm{~mm})$ and was significantly different from the following resins: Dencôrlay $(0.037 \mathrm{~mm})$, Refine Bright $(0.034 \mathrm{~mm})$, Duralay $(0.033 \mathrm{~mm})$ and Vipicor $(0.032 \mathrm{~mm})$. The Dencôr $(0.028 \mathrm{~mm})$, Dencrilay $(0.029 \mathrm{~mm})$ and Resinlay Speed $(0.030 \mathrm{~mm})$ resins showed intermediate values that were not significantly different from the other 4 materials tested (table 2).

The means values of the marginal discrepancy of the surfaces are represented in the figure 1. There was statistically significant difference between buccal, distal, lingual and mesial surfaces. The buccal surface showed the highest marginal discrepancy

Table 2. Means and standard deviations of marginal discrepancy of the experimental groups.

\begin{tabular}{|c|c|c|}
\hline Acrylic resin & Mean $(\mathrm{mm})$ & Standard Deviation \\
\hline Dencrilay ${ }^{a b^{*}}$ & 0,029 & 0,010 \\
\hline Dencôrlay ${ }^{a c^{\star}}$ & 0,037 & 0,021 \\
\hline Dencôr $r^{\mathrm{ab}}$ & 0,028 & 0,006 \\
\hline Vipicor ${ }^{\mathrm{ac}}{ }^{\star}$ & 0,032 & 0,008 \\
\hline Duralay ${ }^{3 c^{*}}$ & 0,033 & 0,012 \\
\hline Resinlay Speed ${ }^{\mathrm{ab}^{\mathrm{b}}}$ & 0,030 & 0,015 \\
\hline Refine Bright ${ }^{a c^{*}}$ & 0,034 & 0,017 \\
\hline Alike $^{b d^{x}}$ & 0,018 & 0,009 \\
\hline
\end{tabular}

\#Tukey's test - p<0,05

*Different letters indicate statistically significant differences

Turkey test $p<0,05$

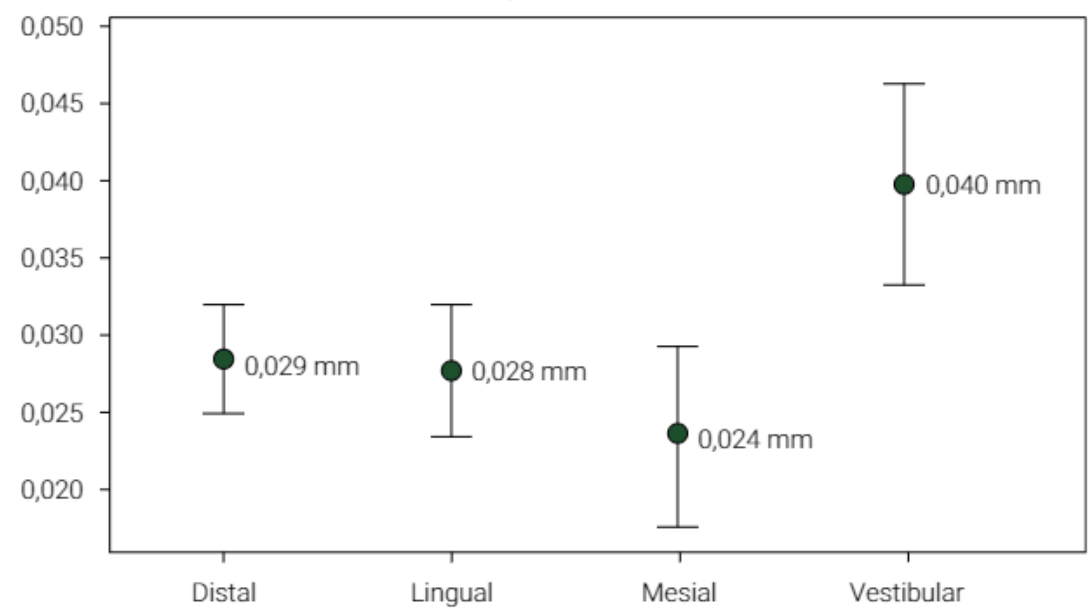

Figure 1. Mean values of the marginal discrepancy of the surfaces independent of the experimental group. 
$(0.040 \mathrm{~mm}$ ) compared to those of other surfaces (distal $0.029 \mathrm{~mm}$, lingual $0.028 \mathrm{~mm}$, and mesial $0.024 \mathrm{~mm})$.

\section{DISCUSSION}

In this study, 8 interim restorative materials were evaluated for marginal fit. The results showed that the mean vertical marginal gap values for the materials tested in this study (range from $0.018 \mathrm{~mm}$ (Alike) to $0.033 \mathrm{~mm}$ (Dencôrlav)) were within a clinical acceptable limit. Celik and Gemalmaz ${ }^{13}$ (2001) and Alfredo Filho et al. ${ }^{14}$ (2003) proposed an acceptable threshold of marginal discrepancy between $0.050 \mathrm{~mm}-0.100 \mathrm{~mm}$. Among the requirements of a proper provisional restoration material, marginal adaptation is the most important one $2,11,12$, since a fine margin may provide health for the prepared tooth as well as its gingival tissues which is necessary for further cementa$\operatorname{tion}^{12}$. Although various studies have reported the marginal gap values of the different provisional materials, the results of all these studies are difficult to interpret and compare with the results of the current study, because of the variations in the sample size, materials used, fabrication techniques, temperature and storage conditions and difference in the methods used for the measurements.

Koumijan and Holmes ${ }^{12}$ (1990) evaluated the marginal accuracy and the effect of water absorption on polymerization shrinkage of seven acrylic resins. Eight specimens of each material were tested under three conditions: immediately after polymerization, after 1 week of dry storage, and after 1 week of storage in room temperature water. The resins Duralay, Cold Pac, and Snap showed 1-week wet storage values $(0.024 \mathrm{~mm}, 0.039 \mathrm{~mm}$ and $0.058 \mathrm{~mm}$, respectively) lesser than the immediate values $(0.039 \mathrm{~mm}, 0.055 \mathrm{~mm}$, and $0.059 \mathrm{~mm}$, respectively). These findings demonstrate the water sorption capacity of the acrylic resins. In this study, the acrylic resin Duralay showed a mean marginal discrepancy of $0.033 \mathrm{~mm}$. This value is consistent with the results of immediately after polymerization $(0.039 \mathrm{~mm})$ reported by Koumijan and Holmes ${ }^{12}$ (1990) and is higher than the value of 1-week wet storage (0.024 mm).

Ehrenberg and Weiner ${ }^{15}$ (2000) examined the effect of water absorption and thermal cycling in the marginal adaptation of the resin Alike (PMMA) and one bis-acrylic resin (Provitec). The authors concluded that there was no significant difference between the resins. However, the thermal cycling time (one year) significantly increased $(p=0,002)$ the marginal discrepancy. This finding indicates it is important to evaluate and adjust restorations to maintain the marginal adaptation of provisional restorations during long rehabilitation treatments. The average marginal gaps found in this study were $323.2 \mathrm{~mm}$ after storage and $460.4 \mathrm{~mm}$ after thermal cycling. These gaps would not be clinically acceptable since they could result in a loss of the cement seal, with resultant dentinal sensitivity, potential for recurrent decay, and gingival inflammation $^{12}$. The mean of marginal discrepancy for the resin Alike was higher than the value found in this study $(0.018 \mathrm{~mm})$. However, this study evaluated the marginal adaptation in a short period of time. Previous studies ${ }^{15-17}$ reported time affects dimensional stability and marginal adaptation. Thus, these results reinforce the provisional nature of crowns made of acrylic resins. 
Ehrenberg and Weiner ${ }^{15}$ (2000) evaluated the marginal adaptation of acrylic resins made from PMMA (Jet, Snap and Alike) following occlusal load and thermal cycling. The results showed that before the treatment (thermal cycling and occlusal contact with the antagonist) there was no significant difference between the groups. However, after treatment, the Alike resin showed a lower marginal discrepancy value $(0.115 \mathrm{~mm})$. This value was higher than the result found in this study $(0.018 \mathrm{~mm})$, despite the absence of occlusal contact with the antagonist, the simulation of a buccal environment, and other differences in methodology.

Another factor that can affect the shrinkage of polymerization is the size of the particles. Smaller particles of polymers manipulated with large volumes of monomer can increase polymerization shrinkage because the monomer is available to react in the total volume. $\mathrm{Kim}^{18}$ (2007) investigated the influence of the ratio between powder/liquid on the polymerization shrinkage-strain kinetics of acrylic resins. The author observed that the Alike resin showed polymerization shrinkage of 3,45\% after ten minutes when manipulated using a 3:1 ratio. This shrinkage value was higher than the shrinkage for Jet and Snap resins $(2.69 \%(2: 1)$ and $1.58 \%(3: 1)$, respectively. The PMMA comes in the form of polymer which is powder and monomer which is liquid and has to be hand mixed. In this study the ratio of powder/liquid varied between the tested materials because the experimental model followed the manufacturer's instructions. The ratio of powder/liquid for Dencrilay, Vipicor, and Refine Bright resins was 2:1 and for Duralay, Dencôrlay, Dencôr, Resinlay Speed and Alike resins was $3: 1$. Although the dimensional changes were verified in the samples, in this study the relationship between polymerization shrinkage and marginal adaptation was not evaluated.

The local and storage conditions of the provisional crowns are controversial in the literature. The samples used in this study were maintained in water at ambient temperature ${ }^{12}$ before the final polymerization period to reduce the dimensional changes of the tested materials. Dhilon et al. ${ }^{19}$ (2011) concluded that polymerizing the polymethyl methacrylate resin provisional crowns by direct technique in the water maintained at $20-30^{\circ} \mathrm{C}$ temperature for 10 minutes resulted in better marginal fit and this method can be utilized in clinical conditions for better results. As the temperature of water bath used is increased, marginal discrepancy increases drastically between 5 and 10 minutes of immersion.

Mei et al. ${ }^{20}$ (2015) evaluated the effects of thermal treatment during polymerization on the physical properties of the provisional crowns made from two acrylic resins (Duralay and Trim) and two bis-acrylic resins (Luxatemp and Protemp 4). The marginal discrepancy values of the tested resins made from PMMA (Duralay) were $0.32 \mathrm{~mm}$ at $23^{\circ} \mathrm{C}$, and $0.31 \mathrm{~mm}$ at $37^{\circ} \mathrm{C}$. These values were higher than the result found in this study for the acrylic resin Duralay $(0.033 \mathrm{~mm})$. This might due to the variation in techniques and storage conditions of the samples.

There are a limited number of studies in the literature that compare the marginal discrepancy of the provisional crowns surfaces. In this study, the higher values were found for the buccal surface $(0.040 \mathrm{~mm})$. The buccal surface was the only surface that statistically differed from the others (distal $-0.029 \mathrm{~mm}$, lingual $-0.028 \mathrm{~mm}$, and mesial $-0.024 \mathrm{~mm}$ ). 
However, Al Rifaiy? (2017) evaluated the vertical marginal discrepancy between the crown margin and the resin die of 4 provisional materials at mid of buccal, lingual, mesial, and distal margin areas and did not found statistically significant difference between the means of the four areas of measurement for each group.

Roda et al. ${ }^{21}$ (2007) evaluated the marginal adaptation of ceramic restorations and resins on the mesial, distal, and lingual surfaces for an onlay in a superior pre-molar. The mesial surface $(63.33 \mu \mathrm{m})$ presented a larger slot than the lingual surface $(45.33 \mu \mathrm{m})$. This result was justified by the anatomy because there is a larger cervical concavity corresponding to the beginning of the separation of the buccal and lingual roots. The distal surface $(54.33 \mu \mathrm{m})$ showed no significant difference in relation to the others.

There is a consensus in the literature that none of the materials used for provisional restorations has advantages over the others in terms of marginal integrity after long-term use. Aging procedures can interfere with the marginal adaptation of provisional crowns, which reinforces their provisional nature and the necessity to substitute final restorations ${ }^{1}$.

There are no restorative materials that meet all the ideal provisional restoration prerequisites ${ }^{2}$. The choice of provisional material used must be based on physical properties, manipulation method, durability and cost. The lack of marginal adaptation for provisional crowns suggests a need for relining and adjustments before the cementation. Therefore, dental professionals should choose materials based on the clinical needs of the patient 2,3 .

In view of the diversity of information available in the scientific literature on the characteristics of provisional prosthetic materials and limitations of this study, further studies and clinical trials are recommended and needed for the development of more durable and marginally fit provisional materials.

Within the limitations of this study, it could be concluded that the marginal adaptation of all materials and surfaces tested were within a clinical acceptable limit. The Alike resin showed the best performance compared to Dencôrlay, Refine Bright, Duralay, and Vipicor resins. The buccal surface showed the highest marginal discrepancy than those of the other tested faces.

\section{References}

1. Rakhshan V. Marginal integrity of provisional resin restoration materials: A review of the literature. Saudi J Dent Res. 2015 Jan; 6(1): 33-40. doi: 10.1016/j.sjdr.2014.03.002.

2. Nejatidanesh F, Lotfi HR, Savabi O. Marginal accuracy of interim restorations fabricated from four interim autopolymerizing resins. J Prosthet Dent. 2006 May;95(5):364-7.

3. Rastogi A, Kamble V. Comparative analysis of the clinical techniques used in evaluation of marginal accuracy of cast restoration using stereomicroscopy as gold standard. J Adv Prosthodont. 2011 Jun;3(2):69-75. doi: 10.4047/jap.2011.3.2.69.

4. Kim SH, Watts DC. Polymerization shrinkage-strain kinetics of temporary crown and bridge materials. Dent Mater. 2004 Jan;20(1):88-95. 
5. Strassler HE. Fixed prosthodontics provisional materials: making the right selection. Compend Contin Educ Dent. 2013 Jan;34(1):22-4, 26; quiz 28, 30.

6. Strassler HE. In-office provisional restorative materials for fixed prosthodontics: part 1 - polymeric resin provisional materials. Inside Dent. 2009Apr;5(4):70-4.

7. Al Rifaiy MQ. Evaluation of vertical marginal adaptation of provisional crowns by digital microscope. Niger J Clin Pract. 2017 Dec;20(12):1610-1617. doi: 10.4103/1119-3077.196083.

8. Christensen GJ. Tooth preparation and pulp degeneration. J Am Dent Assoc. 1997 Mar;128(3):353-4.

9. Christensen GJ. The fastest and best provisional restorations. J Am Dent Assoc. 2003 May;134(5):637-9.

10. García-López DA, Rezende CEE, Hiramatsu DA, Nishida CL, Rubo JH. [Long-term dimensional stability of an acrylic resin for provisional crowns with different types of processing techniques]. Rev Odontol UNESP. 2013 May/Jun;42(3):196-203. doi: 10.1590/S1807-25772013000300009. Portuguese.

11. Tjan AH, Tjan AH, Grant BE. Marginal accuracy of temporary composite crowns. J Prosthet Dent. 1987 Oct; $58(4): 417-21$.

12. Koumjian JH, Holmes JB. Marginal accuracy of provisional restorative materials. J Prosthet Dent. 1990 Jun;63(6):639-42.

13. Celik C, Gemalmaz D. Comparison of marginal integrity of ceramic and composite veneer restorations luted with two different resin agents: an in vitro study. Int J Prosthodont. 2002 JanFeb;15(1):59-64.

14. Alfredo Filho M, Vieira LCC, Baratieri LN. Ceramic inlays and onlays: clinical procedures for predictable results. J Esthet Restor Dent. 2003;15(6):338-51; discussion 352.

15. Ehrenberg D, Weiner $\mathrm{S}$. Changes in marginal gap size of provisional resin crowns after occlusal loading and thermal cycling. J Prosthet Dent. 2000 Aug;84(2):139-48.

16. Ehrenberg D, Weiner GI, Weiner S. Long-term effects of storage and thermal cycling on the marginal adaptation of provisional resin crowns: a pilot study. J Prosthet Dent. 2006 Mar;95(3):230-6.

17. Balkenhol M, Knapp M, Ferger P, Heun U, Wöstmann B. Correlation between polymerization shrinkage and marginal fit of temporary crowns. Dent Mater. 2008 Nov;24(11):1575-84. doi: 10.1016/j.dental.2008.07.001.

18. Kim SH. The effect of monomer to powder ratio on polymerization shrinkage-strain kinetics of polymer-based provisional crown and fixed partial denture materials. J Korean Acad Prosthodont. 2007; $45(6): 735-42$.

19. Dhillon MN, Kumar M, D'Souza DSJ. Effect of water temperature and duration of immersion on the marginal accuracy of provisional crowns. Med J Armed Forces India. 2011 Jul;67(3):237-40. doi: $10.1016 /$ S0377-1237(11)60049-X.

20. Mei ML, So SYC, Li H, Chu CH. Effect of heat treatment on the physical properties of provisional crowns during polymerization: an in vitro study. Materials (Basel). 2015 Apr 15;8(4):1766-1777. doi: $10.3390 /$ ma8041766

21. Roda MI, Cara AA, Capp Cl, Camargo MA, Scanavini MA. [Marginal adaptation of laboratory, composite resin and porcelain restauration]. Odonto. 2007 Jan-Jun; 15(29):73-80. doi: 10.15603/2176-1000/odonto.v15n29p73-80. Portuguese. 